\title{
A ECONOMIA POPULAR ENTRELAÇADA COM A ECONOMIA CAPITALISTA: O CASO DOS METALÚRGICOS ORGANIZADOS EM PEQUENAS UNIDADES DE PRODUÇÃO DA SERRA GAÚCHA
}

\section{POPULAR ECONOMY INTERWEAVING WITH CAPITALIST ECONONY: THE CASE OF METALLURGIC WORKERS ORGANIZED IN SMALL PRODUCTION PLANTS IN SERRA GAUCHA}

\author{
I. L. S. CORRÊA $A^{1, *}$ e M. C. B. FISCHER ${ }^{2}$ \\ ${ }^{1}$ Universidade Federal do Rio Grande do Sul, Colégio de Aplicação, Brasil \\ 2 Universidade Federal do Rio Grande do Sul, Faculdade de Educação, Brasil
}

\author{
ARTICLE INFO \\ Article history: \\ Received 2018-07-02 \\ Accepted 2018-08-17 \\ Available online 2018-08-31
}

\begin{abstract}
Palavras-chave: Economia popular. Trabalho metalúrgico. Cooperação. Reprodução do capital.
\end{abstract}

Keywords: Popular economy; Metallurgic work; Cooperation; Capital reproduction.

*Autor correspondente:
E-mail: ivanlivindo@gmail.com

RESUMO. Este artigo faz parte dos estudos de doutorado em educação e tem como objetivo analisar as relações entre as cooperações simples, solidária e comunitária estabelecidas pelos trabalhadores metalúrgicos organizados em pequenas unidades produção da Serra Gaúcha. Essas relações constituem o que estamos denominando de entrelaçamento da economia popular com a economia capitalista. Como estratégia investigativa, realizou-se: uma observação participante junto a seis pequenas unidades de produção localizadas nos municípios de Canela-RS e Caxias do Sul-RS; e uma entrevista semiestruturada com dez trabalhadores que concordaram em participar da pesquisa. Os dados foram analisados com base no materialismo histórico e dialético. Como resultado da investigação observou-se que, a sobrevivência das pequenas unidades de produção depende das redes de cooperação solidárias onde a existência de trabalho não remunerado garante a permanência desses trabalhadores no setor metalomecânico. Observou-se também, que o capital captura as relações solidárias como estratégia de valorização para a sua reprodução ampliada. Também se observou singularidades que estabelecem relações da economia popular e solidária que priorizam a reprodução ampliada da vida que, embora alimente a reprodução do capital transcende essa lógica de acumulação.

ABSTRACT. This paper is part of my doctoral studies in Education and aims to analyze the relationship among simple, solidarity and community cooperation established by metallurgic workers organized in small plants in

\footnotetext{
${ }^{1}$ Este artigo é uma revisão e ampliação de parte da Tese de Doutorado apresentada no Programa de Pós-graduação em Educação da UFRGS, intitulada: "Autonomia, cooperação e conhecimento na experiência de trabalho de metalúrgicos da Serra Gaúcha” (CORRÊA, 2014).
} 
Serra Gaúcha. This relationship constitutes what is being called of popular economy interweaving with the capitalist economy. As investigative strategy a participant observation was done in six small production plants in Canela and Caxias do Sul, in Rio Grande do Sul state; and, a semi structured interview with ten metalworkers who agreed to be part of the research. The data analyses were based on the theoretical references of the historical and dialectical materialism As result was observed that: the small production plants surviving depends on the solidarity cooperation nets, where the existence of non-paid work guarantee the remaining of these workers in the metal mechanic sector; the capital capture the solidarity relationship as strategy of valorizing its wideness reproduction and, the singularities that establish relationships of popular and solidarity economy which prioritize the life wideness reproduction, that, although nurturing the capital reproduction it transcends the accumulation logic.

\section{Introdução}

Ao estudar o processo de trabalho dos trabalhadores metalúrgicos organizados em pequenas unidades de produção da Serra Gaúcha, observou-se que eles estabelecem uma rede de cooperação que ultrapassa a cooperação para a produção de mercadoria. Essa rede chega a estabelecer relações cooperativas que visam à reprodução ampliada da vida, compondo assim o entrelaçamento da economia capitalista com a economia popular. Diante disso objetivou-se analisar as relações entre as cooperações simples, solidária e comunitária estabelecidas pelos trabalhadores metalúrgicos organizados em pequenas unidades produção da Serra Gaúcha.

Entende-se por economia capitalista aquela baseada na valorização do capital através da produção da mais-valia, em que o dono do capital contrata a força de trabalho, compra matéria-prima e os meios de produção em forma de mercadoria e ao produzir uma nova mercadoria com maior valor que os custos de produção. Isto é, a economia capitalista transforma tudo em valor de troca monetária, incluindo os recursos naturais, o trabalho e a cultura. Assim, as redes de cooperação capitalistas são alianças estratégicas baseadas em interesses comuns onde diversas empresas cooperam visando a obter um tipo de "vantagem competitiva imediata. As alianças podem ser com funcionários, consumidores ou outros parceiros" (ALBUQUERQUE, 2011, p. 309).

Como economia popular compreendem-se as trocas monetárias e não monetárias realizadas no âmbito popular, onde as relações de trabalho não envolvem diretamente a produção de mais-valia envolvendo as unidades domésticas de produção, empresas familiares, as organizações não governamentais e o trabalho associado. $\mathrm{Na}$ economia popular, a informalidade aparece como uma estratégia de sobrevivência ou de reprodução ampliada da vida, onde a cooperação, o companheirismo, a coletividade, a solidariedade e a 
ajuda mútua perpassam as relações de produção e comercialização (RAZETO, 2005; TIRIBA, 2001; CORAGGIO, 2000; KRAYCHETE, 2000).

Para realizar a pesquisa, adotou-se, como estratégia investigativa, a observação participante e as entrevistas semiestruturadas. Para a observação participante, um dos pesquisadores trabalhou como aprendiz em uma pequena unidade de produção (Unidade Núcleo - produz maquinas ferramentas para a indústria farmacêutica), onde pode observar o processo de trabalho e as relações de cooperação que se estabelecem tanto internamente como as que se estabelecem com outras unidades produção. Também se observou outras cinco unidades de produção que mantêm relação de cooperação: uma unidade de componentes plásticos, uma unidade de matrizes, uma unidade de retífica, uma unidade de soldagem; e uma unidade de tornearia. As unidades possuem características distintas e podem ser definidas por: unidades fechadas que mantém relação direta com a grande indústria o que pode ser comparada com um "departamento externo da mesma"; unidades semiabertas, que tem um maior grau de independência para conceber e projetar, porém presta serviço exclusivamente para a grande indústria; e, unidades abertas, que atende diretamente a comunidade local e também prestam serviços a grandes indústrias. Num segundo momento do trabalho de campo, 10 (dez) trabalhadores, que concordaram em participar da pesquisa, foram entrevistados.

$\mathrm{Na}$ práxis das unidades investigadas, observa-se uma rede de cooperação com objetivos produtivos, onde se estabelece um processo de troca de serviços, empréstimos de ferramentas com a intenção de possibilitar as pequenas unidades de produção autônoma desenvolver os produtos ou serviços contratados. Essas trocas geralmente ocorrem mediante trocas monetárias ou trocas de serviços. As redes de cooperação capitalistas incorporam em suas relações aspectos da economia popular, mesmo que o objeto principal das unidades de produção, principalmente as unidades fechadas e semiabertas, esteja voltado para a competitividade no setor metal mecânico.

Porém, ao mesmo tempo em que constroem redes de cooperação que visam à permanência no mercado capitalista competitivo, as unidades de produção, principalmente as abertas, constroem redes de cooperação, com características da economia popular. Tais redes realizam a circulação de bens e serviços em que as trocas ocorrem tanto em formas monetária como não monetária e a finalidade das trocas não está vinculadas estritamente ao acúmulo de capital, mas sim a reprodução simples e ampliada da vida (CORAGGIO, 2000; KRAYCHETE; SANTANA, 2012; RAZETO, 2005; KRAYCHETE, 2000). Tal reprodução tem caráter familiar, entendendo a família num sentido ampliado, que envolve relações afetivas que vão além dos laços sanguíneos, incluindo amigos e vizinhos. No caso das unidades abertas e semiabertas, os trabalhadores e os aprendizes também são considerados como parte da família ampliada. 
Para entender a complexa rede de relações que se estabelece entre as pequenas unidades de produção autônomas investigadas, observe a figura 1:

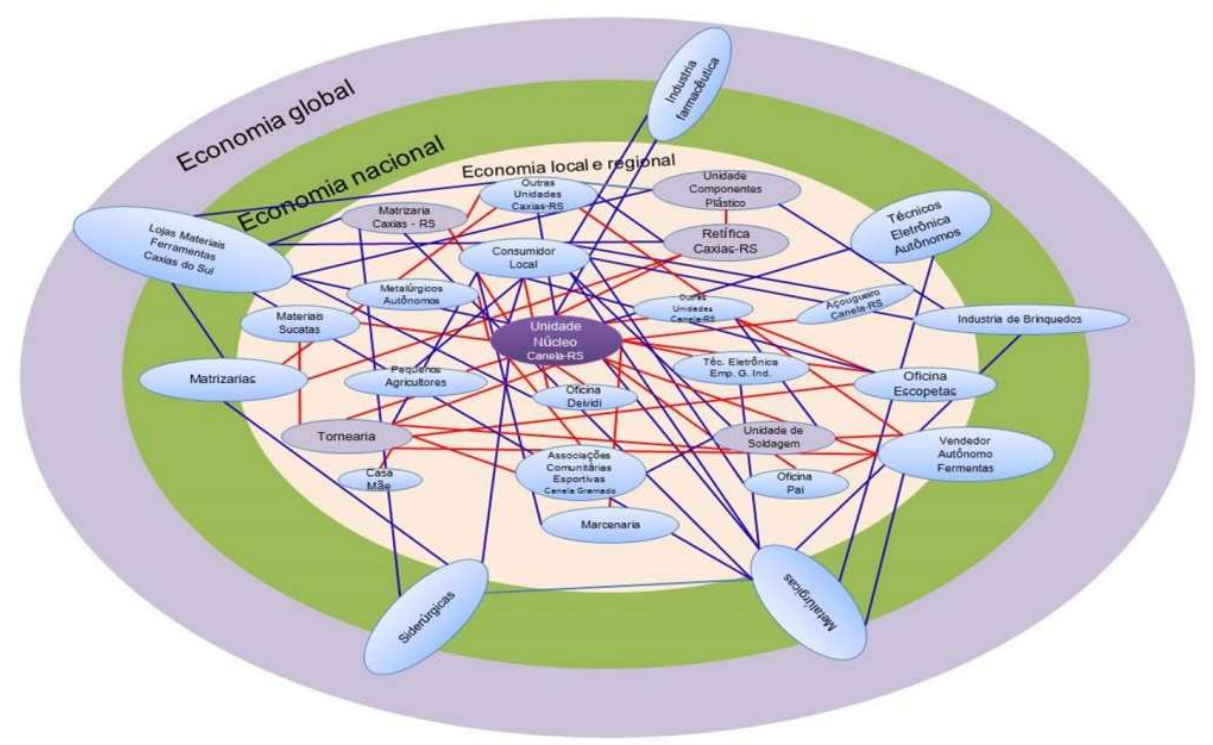

Figura 1: Entrelaçamento contraditório da economia capitalista com economia popular

Fonte: Elaborado pelos autores com base no trabalho de campo

Na figura pode-se observar que as pequenas unidades de produção autônomas que mantêm relação comercial e de produção entre si, atendendo necessidade local e global o que compõe a totalidade. Tal relação é contraditória porque mesmo que a atividade principal esteja inserida na economia capitalista e extraindo mais-valia de outros trabalhadores ou produzindo mais-valia para outras empresas, simultaneamente inserem-se na economia popular, ao produzir bens e serviços com valor de uso estritamente familiar e comunitário. Outro ponto observado é que tais relações solidárias da economia popular acabam sendo incorporadas pelo capital para baixar os valores dos produtos, como se demonstrará na sequência deste capítulo. Como se observa na figura 1, na trama existente entre economia popular e capitalista, tem-se as seguintes relações: capitalista; familiar e solidária. Essas relações estão presentes em todas as unidades observadas, porém, nas unidades fechadas, o relacionamento tem um caráter mais capitalista e as relações, nas unidades abertas, mais solidárias.

Como se pode observar nas conexões em Vermelho e em Azul sendo que o vermelho representa a existência de relações características da economia popular e o azul, as relações 
estritamente da economia capitalista, as conexões em vermelho representam a comercialização e a produção que ocorrem informalmente, onde predominam a troca de serviços e materiais, a ajuda mútua, as relações familiares e comunitárias. As conexões em Azul representam a comercialização e a produção que ocorrem formalmente através de contrato de prestação de serviços ou de produção, onde predomina a circulação de mercadoria (força de trabalho e produto) baseada nas trocas monetárias e na valorização do capital.

\section{A economia popular entrelaçada com a economia capitalista}

\subsection{A valorização do capital nas unidades de produção}

A valorização do capital, segundo Marx $(1985,1988)$ é fruto do processo de trabalho vivo e do trabalho morto. Processo onde o dono do capital compra a matéria prima, a maquinaria e o trabalho vivo em forma de mercadoria e põem-nos em movimento no processo de trabalho para produzir mercadorias. A venda do produto final será superior aos valores pagos pela matéria-prima, a maquinaria e os salários pagos.

Esse processo de produção ocorre no interior de todas as unidades investigadas, sendo que, nas unidades fechadas e semiabertas as relações capitalistas são mais explícitas do que nas unidades abertas. Porém, mesmo que as unidades de produção no seu interior incorporem a lógica de produção capitalista, os trabalhadores proprietários também não deixam de ser assalariados, recebendo pagamento por peça das indústrias que os contrataram. Nesse aspecto, essas unidades não passam de uma extensão da indústria contratante (MARX, 1988). Essa relação leva o trabalhador a explorar o trabalhador, como se pode observar principalmente na Unidade de Componentes Plásticos, na Retífica e na Matrizaria. Essas três unidades são contratadas por outras indústrias para produzir peças ou ferramentas que irão compor um produto final. O contrato que essas indústrias estabelecem é com o trabalhador proprietário, porém o mesmo não conseguindo realizar os serviços sozinho, subcontrata os trabalhadores empregados, dos quais extrai a mais-valia. A diferença dessas unidades de uma grande indústria é que o proprietário trabalha lado a lado com os demais trabalhadores, executando as mesmas tarefas que os demais, além de exercer a função de supervisor.

Segundo o Depoente 4, quem decide o salário por peças é a indústria contratante e, para ele conseguir produzir nesses valores e no tempo estabelecido, ele explora o trabalho temporário de dois trabalhadores. O exemplo dessa unidade é típico da precarização do trabalho imposta pelo processo de reestruturação produtiva do capital, a terceirização leva o trabalhador a exercer sua profissão em situações precárias, sem garantia dos direitos sociais e levando a exploração, no caso dessa unidade, de trabalhadores idosos e aposentados. No 
entanto, o que leva um trabalhador a explorar o outro? Nesse caso singular é o sonho de um dia lançar um produto e conquistar um mercado consumidor e acumular capital.

O Depoente 3, expressa que em nível micro o processo de produção de mais-valia ocorre porque os valores cobrados para realizar os serviços são por hora e os trabalhadores empregados também recebem seus salários por hora. A relação no interior da unidade também é propriamente capitalista, pois para garantir a produção na unidade que the possibilite ter um ganho mensal três vezes superior ao dos trabalhadores empregados, fazer manutenção e compra de máquinas e, pagar os demais custos, o proprietário necessita explorar o trabalho de seis operadores e uma secretária. Como ele paga em média $R \$ 15,00$ a hora para os operadores, a cada hora de trabalho em uma máquina ele obtém um sobre trabalho de $\mathrm{R} \$ 30,00$; dos quais ele desconta os demais custos de produção e um ganho maior por ser proprietário dos meios de produção. Ao analisar isoladamente esse processo, essa unidade tem uma relação propriamente capitalista, porém ao procurar incluí-la num processo produtivo mais amplo, observa-se que Depoente 3 é um trabalhador que desempenha diversas funções na oficina: planeja, coordena e executa parte da produção e está a serviço de outras indústrias.

O mesmo processo acontece na Matrizaria, o Depoente 2 para projetar e produzir um molde precisa contar com o trabalho da esposa, do filho e mais seis trabalhadores. O processo é o mesmo, ele é contratado pela grande indústria para produzir os moldes, recebe para isso um montante que dá para fazer a manutenção e compra de máquinas, pagar os trabalhadores e garantir os salários dos membros da família.

Essas três unidades estão incluídas numa complexa rede de terceirização no setor metalomecânico da Serra Gaúcha que integra micro, pequenas, médias e grandes empresas, porém sem que exista uma centralidade organizacional. Mesmo que essas unidades de produção apresentem uma relação de trabalho baseada na exploração do trabalho encontram-se aspectos cooperativos da economia popular e familiar. Como as empresas fechadas e semiabertas são empresas familiares, segundo Coraggio (2000) sempre é difícil classificá-la justamente porque o proprietário trabalha junto e nas mesmas condições dos seus empregados. Mesmo que as unidades observadas, em seu processo produtivo, apresentem aspectos da economia popular, parece que nas relações de produção nas unidades fechadas e semiabertas perpassam aspectos ou valores liberais.

As falas expressam a ideologia liberal presente no interior das unidades de produção, onde os interesses individuais, de posse e competitivos sobrepõem-se aos interesses coletivos, solidários e de classe. A ideologia liberal é algo que perpassa a totalidade da produção capitalista e atinge todos os espaços sociais, incluindo as relações familiares e da economia popular (CORAGGIO, 2000; TIRIBA, 2001), constituindo-se um pensamento 
comum em toda a sociedade capitalista. Porém, como se verá no próximo item, contraditoriamente, mesmo entre as unidades mais fechadas encontram-se relações de solidariedade nas particularidades e singularidades dos sujeitos da pesquisa.

Nas três unidades abertas, a produção da mais-valia não aparece de forma explícita como nas unidades fechadas e semiabertas porque o trabalho é realizado basicamente pelo trabalhador proprietário. Os trabalhadores empregados atuam com auxiliares do trabalhador proprietário e não existe uma divisão clara das tarefas. O preço dos produtos é calculado pelos salários dos trabalhadores empregados e do trabalhador proprietário.

Segundo os Depoentes 1, 5 e 6 o cálculo do preço do produto está basicamente relacionado ao salário dos trabalhadores e as características do cliente. De alguns pode ser cobrado mais do que de outros, depende muito do produto ou do valor de troca desse produto no mercado. Os valores dos serviços e dos produtos, considerando a forma expressa nas falas dos entrevistados, servem basicamente para as relações da economia capitalista ou dos serviços e produtos realizados para outras indústrias ou clientes com maior capital. Para Coraggio (2000, p. 122), "o mercado é um sistema de relações em que se estabelecem preços com base em relações mecânicas, mas também com base no poder, em acordos ou poderes de regulação ou autorregulação", além de outros fatores comportamentais que se fundem em conhecimentos, valores e visões do mundo. Por isso, a dificuldade de estipular o preço do produto e dos serviços prestados, pois os mesmos dependem das relações competitivas no setor metalomecânico onde estão inseridos.

Outro fator é a relação de trabalho nessas unidades. Há dificuldade de identificar-se um processo explícito de produção da mais-valia, isso porque a produção não está vinculada diretamente a produtividade, isto é, como as encomendas normalmente são peças ou máquinas personalizadas, não existe uma demanda quantitativa e sim uma demanda de qualidade, o tempo de produção desse produto é flexível. Tem peças em que se vai levar mais tempo para produzir que outras e será cobrado o mesmo valor. Tem máquinas que se pensa que irá levar dois meses para fabricar e acaba levando três ou quatro, porém o preço do produto continua o mesmo. A reestruturação produtiva que passou o setor metalomecânico, que introduziu o salário por peça através das terceirizações, nada mais é do que transferir para o trabalhador os custos com os erros de produção e de planejamento. Por exemplo, se para produzir uma máquina em uma indústria que faz o pagamento por tempo, estima-se que levaria 60 dias e devido aos imprevistos leve 90 dias, o tempo de trabalho e o salário pago aos trabalhadores aumentaria $50 \%$. Porém, ao efetuar o pagamento por peça, o tempo de trabalho não previsto vai ser trabalho não pago. Contudo, ao analisar a salário por peça, Marx (1985, p.140) afirma que "o salário por peça se torna fonte mais fecunda de descontos salariais e de fraudes capitalistas". Esse fato não é ignorado pelos sujeitos da pesquisa, como aparecem nas falas: "se o serviço atrasar o problema é do trabalhador". Todos os 
entrevistados receiam os períodos de crise de produção no setor, o que leva a uma perda expressiva dos seus salários, além de não conseguir manter o emprego dos trabalhadores empregados, que compõem a família ampliada.

Porém, existem outras formas de calcular o preço dos produtos e serviços que não são tão simples assim, porque dependem da demanda da comunidade, tem produtos que não podem ser calculados pelo tempo, nem pelo valor de mercado e sim pelo seu valor de uso ou pelo costume. Muito do que é produzido, principalmente nas unidades de produção abertas, tem como finalidade atender a vizinhança e os costumes locais.

\subsection{A reprodução da vida e o caráter familiar das unidades}

O aspecto familiar está presente em todas as unidades investigadas. O caráter familiar dá-se em três aspectos: ocupação familiar dos espaços de trabalho; trocas de serviços; garantia de emprego dos membros da família.

A ocupação familiar dos espaços de trabalho observou-se nas relações dos Depoentes 2 e 3 (Irmãos); do Depoente 6 com sua mãe; do Depoente 1 com os genros e do Depoente 5 que trabalha em "um puxadinho" anexo a sua casa e ao lado da casa do seu pai. A troca de serviços entre os membros familiares observou-se na Unidade Núcleo, onde os seu genros realizam pequenos serviços para o Depoente 1. E também, na Unidade de Componentes Plásticos e na Retífica, os Depoentes 2 e 3 ocupam o mesmo espaço e trocam serviços entre si. Nessas unidades, a garantia de emprego dos membros da família ocorre indiretamente ao dispor-se os espaços de produção para pessoas da família ampliada trabalharem para si próprios. Já na Matrizaria, a ocupação dos espaços e a garantia do emprego da família dãose diretamente porque Depoente 2 e esposa e Depoente 10 (filho) trabalham juntos e mesmo em época de crise, mantêm-se empregados juntamente com os trabalhadores mais antigos e que possuem relações afetivas, próprias da família ampliada. Para Corággio (2000, p. 135), o aspecto familiar da Economia Popular levanta um tema a ser analisado que é a "relação entre produção e reprodução".

O processo produtivo nas unidades observadas vai, além da simples reprodução do capital, o objetivo não é somente a produção de mercadoria, a valorização e o acúmulo de capital. Está presente o aspecto de reprodução da vida. Seria "impossível separar as atividades de produção e comercialização de bens e serviços das circunstâncias de reprodução da vida da unidade familiar destas pessoas" (KRAYCHETE, 2000, p. 36). As relações construídas nas unidades de produção vão além das relações de produção capitalista, porque tanto a ocupação dos espaços, as trocas de serviços e o emprego familiar não têm como objetivo a valorização e reprodução do capital, mas, prioritariamente a reprodução da vida. 
A vinculação do trabalho com a vida familiar é uma das características das unidades observadas, "é um bolo" como expressa o Depoente 1, os membros da família participam na oficina de diversas formas: tanto auxiliando na produção, como utilizando os espaços da oficina para realizar trabalhos para si próprios. Exemplo é a participação dos Genros do Depoente 1: um dos genros além de ocupar o "puxadinho" faz uso das ferramentas da Unidade Núcleo para fazer pequenos consertos em automóveis; o outro genro, como é técnico em eletrônica está sempre auxiliando na resolução de problemas elétricos e eletrônicos das máquinas que o Depoente 1 constrói. Outro exemplo mais relacionado à família ampliada é em relação ao trabalhador empregado na Unidade Núcleo, que utiliza o espaço e as ferramentas da oficina para produzir para si próprio.

Também se observou na relação dos Depoentes 3 e 4 que a relação familiar levou os dois a dividirem o mesmo pavilhão, onde ambos trabalham autonomamente, mas compartilham a mesma estrutura, vestiários, escritório e água, além do auxílio mútuo quando aumenta a demanda de serviços. Na Matrizaria, praticamente a base da produção é familiar, homem, mulher e filho projetam e desenvolvem os moldes.

As relações familiares observadas coincidem com o que Coraggio (2000, p. 106) já constava que "é de se esperar que cada unidade doméstica combine, à sua maneira, os seus próprios recursos e capacidades, e que o faça de diversas formas, inserindo-se de maneiras diversas ao longo do seu ciclo vital”. A combinação existente nas unidades de produção entrelaçam os interesses de reprodução da vida, da família com a reprodução do capital. Entre os seis trabalhadores proprietários constatou-se que o sonho de que o próprio negócio venha num futuro próximo crescer e tornear-se uma grande empresa está presente em quatro trabalhadores proprietários e pode ser sintetizado na fala do Depoente 5, para quem "existe dois tipos de pessoas: uma que vai querer sempre ser funcionário e uma que vai querer ser um patrão ou um gestor". O "querer ser um patrão" pressupõe a visão capitalista dos sujeitos da pesquisa, porque ser patrão necessariamente está vinculado a contratar empregados que venham a produzir para o patrão que possui capital e necessita de força de trabalho para a sua valorização.

Parece que essa relação patrão-empregado tem significado diferenciado na Unidade Núcleo e na Tornearia, onde o trabalho é centrado nas habilidades e capacidades produtivas dos trabalhadores proprietários e seus auxiliares. Estes acabam ocupando temporariamente o papel de empregados, construindo uma relação que Enguita (1989) denomina de família ampliada. Tanto o Depoente 1 como Depoente 6 apontam alternativas para seus empregados num futuro próximo trabalharem por conta própria. O Depoente 1 possibilita ao seu trabalhador empregado realizar serviços autônomos no próprio espaço de trabalho e o Depoente 6 está se preparando para deixar a tornearia para seu Aprendiz (Depoente 7). Relações essas confirmadas pelas observações e entrevistas realizadas com os Depoentes 7 e 8 . 


\subsection{A contradição: solidariedade e valorização do capital}

A contradição observada é que as relações de produção construídas nas unidades encontram-se entre os interesses de solidariedade sem fins lucrativos e os interesses individuais de acúmulo de capital, sendo que nas unidades fechadas e semiabertas predominam os interesses de acúmulo de capital e nas unidades abertas predomina a solidariedade. Porém, a contradição existente é que a solidariedade só é possível porque os sujeitos possuem certo acúmulo de capital que lhes garante disponibilizar certos recursos à coletividade e o acúmulo de capital. Isto, só foi possível, porque existe um espaço cultural solidário o qual possibilitou o sujeito produzir, comercializar e acumular capital. Para entender essa contradição, centrar-se-á na análise da história de construção e nas relações estabelecidas pela Unidade Núcleo, a qual se assemelha à maioria das pequenas unidades criadas no processo de reestruturação produtiva da Serra Gaúcha. A solidariedade nessas unidades de produção tem outra dimensão que a existente entre empregados da grande indústria que se organizam com o objetivo de sobrevivência e na luta contra a opressão do capitalista proprietário dos meios de produção. A solidariedade está mais próxima da ajuda mútua, no sentido de reprodução ampliada da vida, visando ao auxílio para que "os companheiros" os quais se encontram como empregados, amanhã sejam capazes de trabalhar por conta própria.

A ideia de trabalhar por conta própria surge fruto do processo de reestruturação produtiva do capital que adotou a terceirização de parte do processo produtivo e de serviços. Esse processo precarizou as relações trabalhistas, transformando um contingente significativo de trabalhadores experientes em trabalhadores desempregados e subempregados. No que se refere a esse processo, Kuenzer (2005) denominou de "exclusão includente" onde o capital exclui o trabalhador dos postos de trabalho com carteira assinada e inclui os mesmos através da terceirização e da subcontratação. Porém a inclusão não ocorre de forma espontânea, o trabalhador para se incluir necessita de uma rede de cooperação informal e solidária para a sua inclusão. A cooperação informal ou solidária depende das relações de amizades e da solidariedade dos antigos companheiros de trabalho, tanto em forma associada de produção quanto através de empréstimos de espaços, ferramentas e troca de serviços.

As relações construídas durante o tempo de trabalho como empregado criam as condições necessárias para a construção do próprio espaço de trabalho. No caso do Depoente 1, as relações de amizade e companheirismo que levaram o abandonar o emprego e a se aventurar no trabalho por conta própria. Isto se deu juntamente com dois colegas de trabalho, contraditoriamente, isto, também foi um dos motivos de rompimento dessa relação, porque enquanto o Depoente 1 agia na "camaradagem", seus colegas tratavam-no como um 
empregado que tinha uma participação nos lucros. Aqui, aparece a dificuldade de realizar-se um trabalho em sociedade, sem que exista uma compreensão ampliada da divisão do trabalho e dos excedentes. Tanto o Depoente 1 com o Depoente 6 relatam a dificuldade de trabalhar de forma associada, eles preferem trabalhar sozinhos.

Segundo o Depoente 1, essa dificuldade estaria na divisão das tarefas e na divisão das sobras ou dos excedentes. O que o levou ao rompimento desse processo foi que a divisão das sobras ocorria pela quantidade de capital investido e não pela quantidade de trabalho investido no processo produtivo. A divisão das sobras parece que é uma questão cara para todo o trabalho associado, observa-se nos estudos de Tiriba (2001) e Santos (2010) que o princípio de igualdade seria o mais aceito entre os trabalhadores associados. Porém, como no caso estudado por Santos (2011), essa igualdade estaria vinculada à cota de capital investido de cada associado. Isso leva a pergunta, se numa produção associada deva-se valorizar o capital ou o trabalho? Parece que essa é uma contradição inerente ao capitalismo, onde o trabalho é o principal elemento de valorização do capital, porém o capital acumulado apresenta-se como um valor absoluto em relação ao trabalho vivo. Mesmo numa produção associada, parece que o trabalhador tem que produzir mais-valia, a qual será apropriada proporcionalmente ao capital investido no processo.

Essa foi a reclamação do Depoente 1, em relação aos seus sócios, ele trabalhava o dobro do tempo de seus sócios, porém o excedente de seu trabalho era dividido em partes proporcionais ao capital investido. A relação estabelecida nessa sociedade foi que os sócios investidores não dispensavam tempo de trabalho para valorizar seu capital, a valorização dava-se pelo tempo de trabalho majoritariamente de um dos sócios. A relação entre os sócios dava-se da mesma forma patrão-empregado, porque o Depoente 1 além de produzir para a sua subsistência, tinha que produzir excedente para valorizar o capital investido por ele e seus sócios. Foi essa relação de exploração que levou o Depoente 1 a trabalhar por conta própria.

Contudo, o trabalho por conta própria depende das relações solidárias estabelecidas no âmbito familiar, entre amigos e na comunidade local. O trabalho por conta própria do Depoente 1 inicia com a venda de um serviço ou de uma ideia de um produto, o processo produtivo vai ocorrer em casa, em local emprestado ou através de trocas de serviços com outras unidades autônomas. O Depoente 1, antes de construir o espaço de sua oficina, construía apenas "peças pequenas" que "pudesse montar em qualquer lugar emprestado". Hoje, após construir o próprio pavilhão, ele continua contando com o empréstimo de ferramentas e cedendo espaço e ferramentas para outros trabalhadores que se encontram em mesma situação ou iniciando no trabalho por conta própria. Como exemplo, tem-se: o Depoente 5 que se encontra em processo de construção de sua unidade e o Depoente 8 que utilizam os espaços e ferramentas da Unidade Núcleo com a finalidade de produzir para si, além de outros trabalhadores que vão à oficina pedir emprestado ferramentas e usinar peças. 
Do mesmo modo, Depoente 1 utiliza-se dos espaços e ferramentas de outras unidades, por exemplo: para produzir peças em quantidade, solicita os serviços da Matrizaria em Caxias do Sul-RS e pede emprestado aos Depoentes 5 e 6 ferramentas e materiais.

Contraditoriamente, essa solidariedade, onde predomina a ajuda mútua, a valorização da vida é incorporada ao processo produtivo no sentido de redução dos custos de produção e, consequentemente, vai influenciar no valor final da mercadoria, contribuindo, assim, para a reprodução ampliada do capital. A solidariedade, aqui, em muitos aspectos, representa o trabalho não pago pelo capital, isso porque no momento que um trabalhador realiza um trabalho de usinagem sem cobrar ou porque vai ser reposto por outro serviço, esse trabalho não remunerado faz com que se reduza o preço da mercadoria e fique mais competitivo no mercado.

Como exemplo, analisou-se o processo de construção dos gatilhos de escopeta. Este processo foi observado desde a produção propriamente dita até a comercialização do produto. Um cliente do Depoente 1, solicita a produção de 100 gatilhos de escopeta, Depoente $1 \mathrm{em}$ conversas com seu auxiliar e com o cliente projetam o gatilho modificando um modelo já existente. O Depoente 1 leva 10 horas para projetar o gatilho, o auxiliar leva oito horas para usinar um gatilho para ser testado pelo cliente. O gatilho necessita de alguns ajustes, Depoente 1 leva mais oito horas para fazer os ajustes e modificar o projeto. Depois de feitos os ajustes, Depoente 1 leva o projeto e o material para usinar os gatilhos na Matrizaria em Caxias do Sul-RS, o Depoente 10 leva quatro horas para programar e usinar as peças. Depoente 1 retorna a Canela-RS, o auxiliar leva mais seis horas para tirar as rebarbas e mais 20 horas para fazer os furos e as roscas nos gatilhos. Novamente, Depoente 1 retorna a Caxias dos Sul para fazer o tratamento químico dos gatilhos, retorna a Canela-RS e entrega os gatilhos ao cliente. Somando as horas de trabalho e o material utilizado aproximadamente têm-se os seguintes valores:

\section{Tabela 1: Exemplo de como a solidariedade e incorporada pelo capital}

\begin{tabular}{l|r|r}
\hline \multicolumn{1}{c|}{ Horas de trabalho e material utilizado } & \multicolumn{1}{c}{ Valor hora } & \multicolumn{1}{c}{ Total } \\
\hline - 34 horas de trabalho do Auxiliar & $\mathrm{R} \$ 30,00$ & $\mathrm{R} \$ 1.020,00$ \\
- 18 horas de projeto e ajustes do Depoente 1 & $\mathrm{R} \$ 30,00$ & $\mathrm{R} \$ 540,00$ \\
- 8 horas de transporte - Depoente 1 & $\mathrm{R} \$ 30,00$ & $\mathrm{R} \$ 240,00$ \\
- 4 horas de trabalho do Depoente 10 & Solidária & Solidária \\
- Combustível e pedágio do carro do Depoente 1 & $\mathrm{R} \$ 100,00$ & $\mathrm{R} \$ 100,00$ \\
- 1 hora de trabalho de tratamento químico & Solidária & Solidária \\
- Uma chapa de alumínio (1 Mt $x 1 \mathrm{Mt} \times 3 / 4,5 \mathrm{~m} / \mathrm{m})$ & $\mathrm{R} \$ 50,00$ & $\mathrm{R} \$ 50,00$ \\
- Gastos com energia e uso das ferramentas & & $\mathrm{R} \$ 650,00$ \\
\hline Total & & $\mathbf{R} \$ \mathbf{2 . 6 0 0 , 0 0}$ \\
\hline
\end{tabular}

Fonte: Os autores 
Nessa tabela, tentou-se demonstrar como é cobrado o valor de $\mathrm{R} \$ 26,00$ por gatilho projetado e produzido pela Unidade Núcleo, contando com sua rede de cooperação. Como esse trabalho é feito em forma de "Cabrito" quem estipula a valor da hora extra é o próprio auxiliar que cobra em média $\mathrm{R} \$ 30,00$. O Depoente 1 cobrou o mesmo valor por hora tanto para projetar como para levar o material a ser usinado em Caxias do Sul-RS, porém só foi possível fazer um preço de $\mathrm{R} \$ 26,00$ por peça, porque o Depoente 10 não cobrou o trabalho de usinagem, nem a Unidade de Tratamento Químico cobrou o serviço, por ser uma pequena quantidade de alumínio a ser tratada. Já o consumidor final, ao comprar o gatilho na loja vai pagar $\mathrm{R} \$ 60,00$ reais o gatilho, o trabalho solidário não pago é acumulado pelo dono do capital que contratou os serviços de construção do gatilho e que realiza a comercialização do mesmo. Porém, o cliente que encomendou os gatilhos não pode ser considerado como um explorador só porque encomendou os serviços, ele também trabalha por conta própria e só consegue comercializar os gatilhos porque a rede de cooperação solidária estabelecida na região possibilita a produção de uma mercadoria com qualidade e com preço inferior aos produtos similares existente no mercado. No entanto, a lógica é a mesma estabelecida pelo grande capitalista ao terceirizar serviços, reduz-se o custo de produção porque incorpora o trabalho solidário na mercadoria e consegue um acúmulo maior de capital graças ao trabalho solidário não remunerado.

Mas a solidariedade observada durante o processo de produção e que perpassa as redes de cooperação estabelecidas pela pequena unidade de produção não se restringe aos aspectos produtivos, essa solidariedade faz parte das relações culturais dos trabalhadores que em sua experiência cotidiana percebem que para sobreviver na sociedade capitalista necessitam estabelecer uma rede de ajuda mútua. Como ensina Tiriba (2001, p. 349) "a solidariedade é um elemento fundamental que acompanha a convivência cotidiana dos setores populares. Ela é uma das condições para preservar e melhorar a qualidade de vida e, ao mesmo tempo, é um dos elementos constitutivos das relações econômicas". Outro aspecto da contradição é que a rede de cooperação estabelecida pelas pequenas unidades de produção autônomas principalmente pelas unidades abertas parece que recupera para a comunidade local: os conhecimentos e os meios de produção que anteriormente só tinham acesso através do consumo de produtos em que sua produção e concepção eram alheias à cultura local.

A Unidade Núcleo ao mesmo tempo em que incorpora trabalho solidário para produzir com baixo custo, máquinas-ferramentas para a indústria farmacêutica de capital internacional, dispõe desse conhecimento para produzir pequenas ferramentas para a comunidade local.

A incorporação do trabalho solidário local ao capital global não se dá apenas nas usinagens de peças não remuneradas, envolve outras trocas de serviços como: a) para fazer o polimento das peças, o Depoente 1 precisa da Esmerilhadeira de Chicote emprestada pelo 
Depoente 5; b) para instalar a parte elétrica e eletrônica das máquinas ele conta com trabalho solidário de um dos seus genros (Técnico em Eletrônica e Eletrotécnica) que é trabalhador empregado na Empresa A e fora do horário faz a instalação e programação das máquinas; c) utiliza, no processo produtivo, materiais doados por sucatas e outras unidades de produção que compõem a rede. São exemplos de como a solidariedade constituinte do processo produtivo é capturada para a valorização do capital. Com isso, aponta-se que a reestruturação produtiva do capital não somente captura a subjetividade do trabalho vivo (ANTUNES, 2009; SANTOS, 2010; ALVES, 2011), manifestado através da criatividade, engenhosidade e trabalho em equipe, como captura os aspectos culturais de solidariedade do trabalhador como forma de valorização do capital.

Para Tiriba (2001, p. 236) a subjetividade do trabalhador não pode ser entendida somente como as "relações vividas no ambiente de trabalho, mas constrói-se e se reconstrói a partir das diferentes experiências vividas em diferentes macroprocessos e redes complexas que se apresentem como expressão dos diversos planos de uma realidade histórico-social mais ampla". A complexidade das redes de cooperação observadas envolve aspectos de solidariedade que vão além das relações de produção, contribuindo para a construção de relações comunitárias locais que possibilitam a socialização de meios de produção adquiridos no processo de reestruturação produtiva do capital.

Porém, contraditoriamente, os sujeitos pertencentes às classes populares apropriamse dos meios de produção que anteriormente pertenciam aos grandes capitalistas e, hoje, através da complexa rede de cooperação solidária, conseguem produzir bens e serviços baseado na lógica da economia popular e não na lógica da economia capitalista. Como exemplo, tem-se a produção de ferramentas para outras unidades familiares e instituições: marcenarias, açougues, pequenos agricultores, centros comunitários, escolas, entre outras. Quando um membro da comunidade procura os serviços da pequena unidade de produção, já sabe que os serviços serão feitos basicamente em forma de "favor" ou por um preço simbólico.

Como exemplo de preço simbólico, foi o da produção de uma ferramenta para cortar casca de laranja. Para projetar e produzir a ferramenta, ocupou-se aproximadamente 10 horas de trabalho do Depoente 1 e 10 horas de trabalho do Depoente 8, mais o material utilizado e os gastos com máquinas e ferramentas. Se fosse utilizar o mesmo cálculo para a produção dos gatilhos essa ferramenta sairia pelo valor de $R \$ 800,00$. Porém como é uma ferramenta que será utilizada para a produção na economia popular foi cobrado o valor simbólico de $R \$$ 200,00 e quem recebeu o valor foi o Depoente 8 como forma de pagamento do trabalho extra. Segundo Coraggio (2000), uma das características da economia popular é que existe uma diversidade das formas de remuneração e que não chega a possibilitar acumulação de capital, 
necessitando do trabalho constante para garantir a reprodução da vida. Nesse aspecto, tanto os consumidores locais como as unidades de produção investigadas enquadram-se nessa característica porque a reprodução ampliada da vida depende do trabalho, pois não possibilita o acúmulo de capital necessário para viver de investimentos.

\section{Considerações finais}

A solidariedade presente na cultura do trabalho tem forte apelo à melhoria econômica dos membros da comunidade e da reprodução ampliada da vida, ainda distante de uma consciência de classe. Contudo, mesmo que essa cultura do trabalho não incorpore aspirações transformadoras ou de envolvimento ativo na política de Estado, ela contribui significativamente para a construção de uma consciência de classe. Conforme Thompson (1987a, p. 10), a consciência de classe é a forma como experiências de trabalho "são tratadas em termos culturais: encarnadas em tradições, sistemas de valores, ideias e formas institucionais". Para esse autor não existe uma forma única do surgimento da consciência de classe e depende muito da experiência acumulada dos sujeitos sociais. Com base nesse autor, Vendramini e Tiriba (2011, p. 13), o conceito de classe "não se tratar de um conceito estático, a análise da classe trabalhadora hoje, na sua complexidade, pressupõe a análise de seu (re)fazer-se no processo histórico". Sendo assim, ao estudar: como os trabalhadores reorganizam-se no trabalho, no contexto da reestruturação produtiva e suas redes de cooperação produtiva e solidárias, as redes, permeadas pelos costumes comunitários locais podem ser pensadas como manifestações de consciência de classe. Isto, porque se constituem em formas de resistência à lógica do capital de transformar tudo e todos em mercadoria com determinado valor de troca. Sendo assim, isto é a reprodução ampliada da vida em conflito com a reprodução ampliada do capital.

Assim pode-se concluir que, na particularidade regional, a sobrevivência das pequenas unidades de produção autônomas depende das redes de cooperação solidárias onde a existência de trabalho não remunerado garante a permanência desses trabalhadores no setor metalomecânico. Em outras palavras, o capital captura as relações solidárias como estratégia de valorização para a sua reprodução ampliada. Também se observou singularidades que estabelecem relações econômicas populares e solidárias que priorizam a reprodução ampliada da vida que, embora alimente a reprodução do capital transcende essa lógica de acumulação. 


\section{Referências}

ALBURQUERQUE, Paulo Peixoto. Redes de cooperação. In. CATTANI, Antônio David; HOLZMANN, Lorena. (Orgs.). Dicionário de trabalho e tecnologia. Porto Alegre: Zouk, 2011. p. 307-310.

ALVES, Giovanni. Trabalho e subjetividade: o espírito do toyotismo na era do capitalismo manipulatório. São Paulo: Boitempo, 2011. 164 p.

ANTUNES, Ricardo. Os sentidos do trabalho: ensaio sobre a afirmação: negação do trabaIho. 3 ed. São Paulo: Boitempo, 2009. 287 p.

CORAGGIO, José Luiz. Da economia dos setores populares à economia do trabalho. In.KRAYCHET, Gabriel; LARA, Francisco; COSTA, Beatriz (Orgs.). Economia dos setores populares: entre a realidade e a utopia. Petropolis: Vozes; Rio de Janeiro: Capina; Salvador: CESE: UCSAL, 2000. p. 91-141.

CORRÊA, Ivan Livindo de Senna. Autonomia, cooperação e conhecimento na experiência de trabalho de metalúrgicos da Serra Gaúcha. Porto Alegre: UFRGS, 2014. (Tese apresentada ao Programa de Pós-Graduação em Educação da UFRGS em maio de 2014).

ENGUITA, Mariano Fernández. A face oculta da Escola. Porto Alegre: Artes Médicas, 1998. FISCHER, Maria Clara; TIRIBA, Lia. Saberes do Trabalho Associado. In. CATTANI, Antônio David; et. all. Dicionário internacional da outra economia. São Paulo: Almedina, 2009. p. 293298.

KRAYCHETE, Gabriel. Economia dos setores populares: entre a realidade e a utopia. In.KRAYCHET, Gabriel; LARA, Francisco; COSTA, Beatriz (Orgs.). Economia dos setores populares: entre a realidade e a utopia. Petropolis: Vozes; Rio de Janeiro: Capina; Salvador: CESE: UCSAL, 2000. p. 15-37.

KRAYCHETE, Gabriel; SANTANA, André. Economia dos setores populares e inclusão socioprodutiva: conceitos e políticas públicas In. Mercado de trabalho: conjuntura e análise / Instituto de Pesquisa Econômica Aplicada; Ministério do Trabalho e Emprego. n.52, agosto, 2012. Brasília: Ipea: MTE, 2012. p. 55-62.

KUENZER, Acácia Zeneida. Exclusão includente e inclusão excludente: a nova forma de dualidade estrutural que objetiva as novas relações entre educação e trabalho. In: SAVIANI, Dermeval; SANFELICE, José Luís; LOMBARDI, João Claudinei. (Orgs.). Capitalismo, trabalho e educação. 3. ed. Campinas: Autores Associados, 2005. p. 77-96.

LUKÁCS, György. História e consciência de classe: estudos sobre a dialética marxista. São Paulo: Martins Fontes, 2003. 598 p.

MANCE, Euclides André. Redes de Colaboração Solidária. In. CATTANI, Antônio David; et. all. Dicionário internacional da outra economia. São Paulo: Almedina, 2009. p. 278-283. 
MARX, Karl. O capital: crítica da economia política. Tradução Regis Barbosa e Flávio R. Kothe. Livro Primeiro. Volume I. Tomo I (os economistas). 3 ed. São Paulo: Nova Cultura, 1988. 287 p.

MARX, Karl. O capital: crítica da economia política. Tradução Regis Barbosa e Flávio R. Kothe. Livro Primeiro. Volume I. Tomo II (os economistas). 2 ed. São Paulo: Nova Cultura, 1985. 306 p.

MÉSZÁROS, István. O poder da ideologia. São Paulo: Ensaio, 1996.

RAZETO, Luis. Economia de solidariedade e organização popular. In. GADOTTI, Moacir; GUITIÉRREZ, Francisco. Educação comunitária e economia popular. 4 ed. São Paulo: Cortez, 2005. p. 34-58.

SANTOS, Geraldo Márcio Alves dos. Pacto para viver: a mobilização de saberes na produção associada, gestão e organização do processo de trabalho e maquinaria em uma indústria metalúrgica. Niterói: UFF, 2010. Tese (Doutorado em Educação) - Programa de pós-graduação em Educação, Faculdade de Educação, Universidade Federal Fluminense- UFF, 2010. THOMPSON, E.P. A formação da classe operária Inglesa. Volume I. Rio de Janeiro: Paz e Terra, 1987a. 204 p.

TIRIBA, Lia. Educação popular e cultura do trabalho: pedagogia(s) da produção associada. ljuí: Ed. UNIJUÍ, 2001. 400 p.

VENDRAMINI, Célia Regina; TIRIBA, Lia. Classe, cultura e experiência na obra de $\mathbf{E}$. $\mathbf{P}$. Thompson: contribuições para a pesquisa em educação. In. 34ํㅗㄹ Reunião Anual da ANPEd Associação Nacional de Pesquisa e Pós-Graduação em Educação. Natal-RN: entre 2 e 5 de outubro de $2011.19 \mathrm{p}$. 